\title{
Smoking in young women in Scotland and future burden of hospital admission and death:
}

\author{
a nested cohort study
}

\begin{abstract}
\section{Background}

Many women smoke, yet few longitudinal studies have examined the non-fatal burden of smoking in women.

\section{Aim}

To investigate smoking in young women, and hospital admission and death in Scotland; and to compare mortality risk with elsewhere in the UK

\section{Design and setting}

Nested cohort study: Royal College of General

Practitioners' Oral Contraception Study, UK.

\section{Method}

A total of 4121 women categorised by smoking

habits and living in Scotland at recruitment

(1968-1969) were followed until March 2009. Cox regression was used to investigate smoking and survival time; mortality from cancer, circulatory, or respiratory disease, and all other causes; and hospitalisation for any reason, and for specific reasons. The number and type of hospital admissions and bed-days were examined by smoking status. Life tables and Cox regression were used to compare the mortality risk of women living in Scotland with that of women living elsewhere.
\end{abstract}

\section{Results}

All-cause mortality was increased in women who smoked $<15$ cigarettes daily ladjusted hazard ratio $=1.99,95 \%$ confidence interval $[\mathrm{Cl}]=1.74$ to 2.27 ) and those who smoked $\geq 15$ cigarettes daily (adjusted $\mathrm{HR}=2.81,95 \% \mathrm{Cl}=2.47$ to 3.20 ) Smoking any amount increased death from cancer, circulatory, respiratory, and other causes. Increased risk estimates were seen in one or both smoking groups for hospitalisation for any cause, and for several specific causes. More smokers than non-smokers were admitted to hospital, for four or more reasons, and had a longer total stay. The median survival age among smokers was lower in Scotland than elsewhere. Higher adjusted hazard ratios for mortality were found among smokers in Scotland.

\section{Conclusion}

This study provides a powerful reminder of the burden of smoking in young women. In the UK, harmful effects appear to be worse in smokers in Scotland.

\section{Keywords}

cohort studies; general practice; hospitalisation; mortality; smoking; women.

\section{INTRODUCTION}

Longitudinal studies have confirmed the relationship between cigarette smoking and an increased risk of death among women. ${ }^{1-5}$ Smoking also changes the pattern of death seen in populations. For example, lung cancer, once rare among women, is now the leading cause of fatal cancer among women in many countries, including the US ${ }^{6}$ and the UK. ${ }^{7-9}$ Despite these well-documented mortality risks, smoking remains common among women. The 2009 General Lifestyle Survey of Great Britain found that onefifth of all women aged $>15$ years were current cigarette smokers, with the highest proportion of women who smoke (24\%) living in Scotland. ${ }^{10}$

Few longitudinal studies have examined the burden of smoking among women in terms of non-fatal outcomes, such as future hospital admissions. ${ }^{11-14}$ Those that have were conducted in countries outside the UK, ${ }^{11-14}$ or examined workforce rather than population-based cohorts. ${ }^{12,14}$ Information from the 1998 Scottish Health Survey has been linked to hospital admission data, and revealed a near doubling of risk of hospitalisation for a serious condition among heavy smokers compared with non-smokers. ${ }^{15}$ However, separate risk estimates were not presented for men and women. This current study examined the relationship between smoking at a young age and future burden of hospital admission and death among a nested cohort of women living in Scotland when recruited to the

L Iversen, PhD, research fellow; PC Hannaford MD, NHS Grampian Chair of Primary Care, Academic Primary Care, Division of Applied Health Sciences; S Fielding. PhD, lecturer in medical statistics, Medical Statistics Team, Division of Applied Health Sciences, University of Aberdeen, Aberdeen.

\section{Address for correspondence}

Lisa Iversen, Academic Primary Care, Division of Applied Health Sciences, University of
UK's Royal College of General Practitioners (RCGP) Oral Contraception Study. ${ }^{16}$ It also investigated whether the mortality patterns associated with smoking in women living in Scotland differed from those in women living elsewhere in the UK.

\section{METHOD}

\section{The RCGP Oral Contraception Study}

The primary aim of the RCGP Oral Contraception Study is to investigate the long-term effects of oral contraception. The study began in 1968, when 1400 GPs throughout the UK recruited 23000 women who were using oral contraception and a similar number of women who had never used oral contraception. ${ }^{16}$ All of the women were married/living as married, 98\% were white, and the mean recruitment age was 29 years (standard deviation, SD = 6.6 years). Recruitment information included the number of cigarettes smoked daily, social class las determined by husband's occupation), ${ }^{17}$ parity, and significant previous medical history. The GPs subsequently supplied, at 6-monthly intervals, details for women still registered with them, of any prescriptions for hormonal preparations, pregnancies, surgery, new illnesses, and deaths. GP observation ended in 1996.

The Oral Contraception Study does not hold any identifiable information about cohort members. Instead, each woman has a unique study number, the key to which was held by the recruiting doctor. In the mid 1970s, $75 \%$ of the original

Aberdeen, Polwarth Building, Foresterhill, Aberdeen, AB25 2ZD.

E-mail: L.iversendabdn.ac.uk

Submitted: 17 April 2012; Editor's response: 28 June 2012; final acceptance: 25 February 2013 CBritish Journal of General Practice This is the full-length article (published online 29 Jul 2013) of an abridged version published in print. Cite this article as: Br J Gen Pract 2013; DOI: 10.3399/bjgp13X670651 


\begin{abstract}
How this fits in
Few longitudinal studies have examined the burden of smoking in women in terms of long-term non-fatal outcomes such as hospital admissions. This study investigated the long-term effects (hospital admissions and mortalityl of smoking in young women, in a nested cohort of women recruited in Scotland to the Royal College of General Practitioners' Oral Contraception Study. Smoking in young women increases their long-term risk of all-cause mortality, death from a variety of specific causes, and subsequent hospital admission loverall, for a variety of different serious conditions, and total length of stay). Long-term harmful effects appear to be greater among smokers living in Scotland, compared with those residing elsewhere in the UK, highlighting that efforts to promote smoking cessation among women need to be particularly strong in Scotland.
\end{abstract}

cohort was 'flagged' at the NHS Central Registries, for notification of subsequent cancers and deaths. The remaining 25\% of the original cohort could not be flagged because they, or their GP, had already left the study. The flagging procedure was done by the recruiting GPs supplying, on the researchers' behalf, identifying information for each woman and her unique study number, directly to the registries.

In 2009, the Information Services Division (ISD) of NHS Scotland contacted, on the researchers' behalf, the NHS Central Registry in Scotland (the General Register Office Scotland, GRO-S), to obtain in the analyses of different outcomes. ISD = Information Services Division

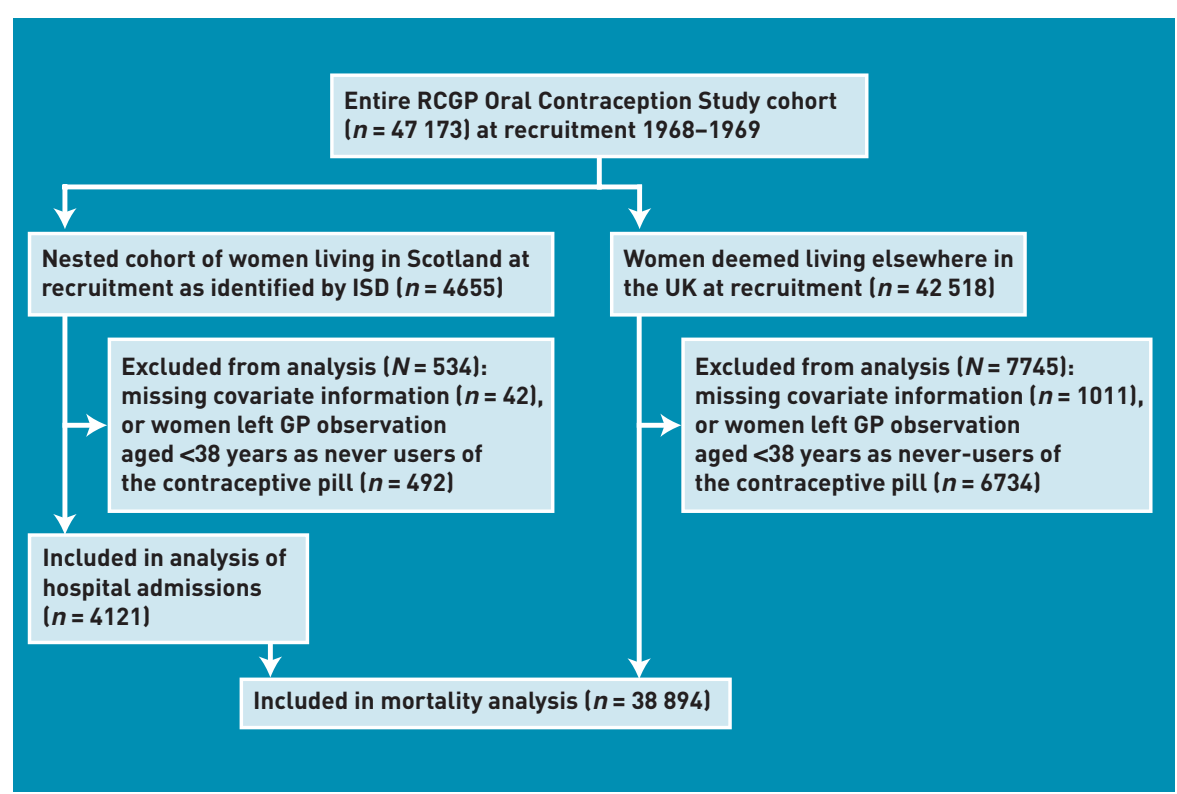

a members and posting listing, which identified all flagged women in the Oral Contraception Study recruited in Scotland. The listing included identifying information for each woman, together with her unique study number. ISD then identified, for each woman, all relevant hospital episodes on the Scottish Morbidity Record (SMR) 01 database from 1968 onwards, before stripping off the identifying information. The hospital episodes were then linked to the Oral Contraception Study database, by use of the unique study number. In 2010, a similar process was undertaken to obtain, where available, hospital episode information for flagged women recruited elsewhere in the UK. This information was only available from 1997.

\section{Nested cohort}

To examine the relationship between smoking at a young age and risk of future hospital admissions and death, all women on the Oral Contraception Study database who were recruited in Scotland and flagged with the NHS Central Registry $(n=4655$; Figure 1) were identified. It was not possible to use hospital information for flagged women recruited elsewhere in the UK because there was likely to be missing information about hospital admissions among individuals who left the study before GP observation ended and 1997, when hospital admission information from elsewhere in the UK first became available. For all women in the nested cohort, recruitment data were extracted from the Oral Contraception Study database about the number of cigarettes smoked daily; social class; oral contraceptive use; and history of serious illness lany of ischaemic heart disease, hypertension, cerebrovascular disease, venous thromboembolism, chronic bronchitis, asthma, diabetes mellitus, and cancer). For history of serious illness, a binary variable was created (no, none of the conditions, or yes, at least one condition).

For each woman the following were then extracted: the date at which a woman recruited as a never-user of oral contraception began using the contraceptive pill; the date at which parity increased; the date at which a woman who had no history of serious illness at recruitment experienced the first episode of the specified serious illnesses; and, if appropriate, the date and cause of death. From the information supplied by ISD, the following were also extracted: the date of the first hospital admission for any reason, and for infectious and parasitic diseases IInternational Classification of Disease 8th revision, ${ }^{18}$ 
[ICD-8] codes 000-136); any cancer (codes 140-209); cancer of the large bowel and rectum (codes 153-154), lung (code 162), breast (code 174), invasive cervix (code 180), uterine body (code 182), or ovary (code 183); other reproductive (code 184) and other cancers (codes 140-209, excluding already specified cancers); mental health problems (codes 290-317); any circulatory disease (codes 390-458); ischaemic heart disease (codes 410-414); other heart disease (codes 420-429); cerebrovascular disease (codes 430-438); other circulatory disease (codes 390-409, 440-458); respiratory disease (codes 460-519); digestive disease (codes 520-577); genitourinary disease (codes 580629); and other conditions not elsewhere specified. The end of follow-up was 31 March 2009.

Women without recruitment information regarding smoking $(n=10)$, parity $(n=3)$, social class ( $n=14$ ), or contraceptive pill status ( $n=15$ ) were excluded; 492 women who had never used oral contraceptives at recruitment and who left the study before the age of 38 years were also excluded, because it was not known whether they subsequently used oral contraceptives. It was assumed that older never-users who left the study were unlikely to start using the contraceptive pill, as $91 \%$ of women in the study who used oral contraceptives did so before 38 years of age.

Approval for the linkage of additional hospital episode data in Scotland was granted by the Privacy Advisory Committee (ref no: 28/08) of ISD.

\section{Statistical analysis}

Data were analysed using IBM SPSS Statistics (version 19) and SAS (version 9.1). Recruitment characteristics were categorised into: smoking (non-smoker, $<15$ cigarettes daily, $\geq 15$ cigarettes daily); and social class (manual, classes I-IIla and husbands recorded as students or commissioned armed forces; non-manual, classes IIIb-V and husbands recorded as non-commissioned armed forces). The recruitment characteristics of the smoking groups in the nested cohort were compared, using $\chi^{2}$ tests for categorical variables and Kruskal-Wallis tests for nonnormally distributed continuous variables. The relationship between smoking status at recruitment and survival time was examined using Cox regression. A model was then fitted, adjusting for age and social class at recruitment, and the timedependent covariates parity $(0,1,2+)$, oral contraceptive use (never, ever), and history of serious illness (no, yes). Risk of mortality from any cancer, circulatory disease, respiratory disease, and all other causes not already specified were each analysed using competing risks, ${ }^{19}$ combined with the time-dependent approach for the adjusted analyses.

For each type of hospital admission, an unadjusted Cox regression model was fitted from the time of recruitment to the date of hospital admission, censored as appropriate at the date of death or end of follow-up. Models adjusting for age and social class at recruitment and the time-dependent covariates of parity, oral contraceptive use, and history of serious illness were also conducted.

Among women who were admitted to hospital at least once, the total number of admissions and total length of stay (in terms of bed-days) were compared by smoking status, using the Kruskal-Wallis test. The number and proportion of: admissions to different specialties, and emergency admissions and inpatient admissions, by smoking status, were also compared, using $\chi^{2}$ tests.

To assess whether the nested cohort was different from the rest of the women in the RCGP Oral Contraception Study, the relationship between smoking and death was examined, since mortality data are available for all women lunlike hospital admission data). First, separate life tables were constructed for women recruited in Scotland ( $n=4121)$ and elsewhere ( $n$ $=38$ 894; Figure 1), stratified by smoking status, and the median survival age in each group was calculated. Next, Cox regression of all women was conducted, which included a variable combining location with smoking status, that is, compared all non-smokers (reference category) with: $<15$ cigarettes daily and living in Scotland at recruitment; $\geq 15$ cigarettes daily and living in Scotland; $<15$ cigarettes daily and living elsewhere in the UK; $\geq 15$ cigarettes daily and living elsewhere in the UK. The time-dependent covariates of parity, oral contraceptive use, and history of serious illness were then adjusted for. Cause-specific mortality (death from any cancer, circulatory or respiratory disease, and all other causes) was then calculated, combining time-dependent covariates with the competing risks method.

\section{RESULTS}

Compared to non-smokers, a larger proportion of smokers were of manual social class, were of higher parity, and had ever used the contraceptive pill (Table 1). By the end of follow-up, 648 women had died, mainly from cancer and circulatory disease 
Table 1. Characteristics of women living in Scotland at recruitment to the RCGP Oral Contraception Study, by smoking status

\begin{tabular}{|c|c|c|c|c|c|}
\hline \multirow[b]{2}{*}{ Characteristic } & \multirow[b]{2}{*}{ All women $(N=4121)$} & \multicolumn{4}{|c|}{ Number of cigarettes smoked daily at recruitment } \\
\hline & & Non-smokers ( $n=2063$ ) & $<15(n=1142)$ & $\geq 15(n=916)$ & $P$-value \\
\hline \multicolumn{6}{|l|}{ Social class, $n$ (\%) } \\
\hline Manual & $2910(70.6)$ & $1341(65.0)$ & $856(75.0)$ & 713 (77.8) & $<0.001$ \\
\hline Non-manual & $1211(29.4)$ & $722(35.0)$ & $286(25.0)$ & $203(22.2)$ & \\
\hline \multicolumn{6}{|l|}{ Parity, $n(\%)$} \\
\hline 0 & 629 (15.3) & 357 (17.3) & $147(12.9)$ & $125(13.6)$ & $<0.001$ \\
\hline 1 & 946 (23.0) & $464(22.5)$ & $285(25.0)$ & $197(21.5)$ & \\
\hline 2 & $1263(30.6)$ & 656 (31.8) & $352(30.8)$ & 255 (27.8) & \\
\hline$\geq 3$ & $1283(31.1)$ & $586(28.4)$ & 358 (31.3) & 339 (37.0) & \\
\hline \multicolumn{6}{|c|}{ Contraceptive pill use status, $n(\%)$} \\
\hline Never used & 1918 (46.5) & 1020 (49.4) & $527(46.1)$ & $371(40.5)$ & $<0.001$ \\
\hline Ever used & $2203(53.5)$ & $1043(50.6)$ & 615 (53.9) & 545 (59.5) & \\
\hline Age, median (IQR), years & $28(24-33)$ & $28(24-34)$ & $28(23-33)$ & $28(24-34)$ & 0.321 \\
\hline
\end{tabular}

(Table 2). One-quarter (238/916; $26.0 \%)$ of those who smoked $\geq 15$ cigarettes daily, $18.5 \%$ (211/1142) of women who smoked $<15$ cigarettes daily, and 9.6\% (199/2063) of the non-smokers died. The hazard ratio (HR) in women who smoked was more than double that of non-smokers (Table 3).
Increasing age and history of serious illness were both independently associated with an increased mortality risk. Non-manual social class, increasing parity, and starting to use the pill during the study were independently associated with a reduced risk of death. After adjustment, the risk of all-cause mortality

Table 2. Cause of death of women living in Scotland recruited to the RCGP Oral Contraception Study

\begin{tabular}{|c|c|c|c|c|c|}
\hline \multirow[b]{2}{*}{ Cause of death } & \multirow[b]{2}{*}{ ICD-8 codes } & \multirow[b]{2}{*}{ Total } & \multicolumn{3}{|c|}{ Number of cigarettes smoked daily at recruitment } \\
\hline & & & $\begin{array}{l}\text { Non-smokers } \\
(n=2063), n(\%)^{a}\end{array}$ & $\begin{array}{c}<15 \\
(n=1142), n(\%)^{a}\end{array}$ & $\begin{array}{c}\geq 15 \\
(n=916), n(\%)^{a}\end{array}$ \\
\hline Any reason & 000-999, all E & 648 & $199(9.6)$ & $211(18.5)$ & $238(26.0)$ \\
\hline All cancer & 140-209 & 287 & $91(45.7)^{b}$ & $97(46.0)^{b}$ & $99(41.6)^{b}$ \\
\hline \multicolumn{6}{|l|}{ Cancer site } \\
\hline Large bowel and rectum & 153,154 & 25 & $11(5.5)$ & $4(1.9)$ & $10(4.2)$ \\
\hline Gallbladder/liver & 155,156 & 2 & - & $1(0.5)$ & $1(0.4)$ \\
\hline Lung & 162 & 78 & $9(4.5)$ & $23(10.9)$ & 46 (19.3) \\
\hline Breast & 174 & 50 & $28(14.1)$ & $16(7.6)$ & $6(2.5)$ \\
\hline Invasive cervix & 180 & 6 & $2(1.0)$ & $3(1.4)$ & $1(0.4)$ \\
\hline Uterine body & 182 & 6 & $2(1.0)$ & $3(1.4)$ & $1(0.4)$ \\
\hline Ovary & 183 & 18 & $11(5.5)$ & $6(2.8)$ & $1(0.4)$ \\
\hline CNS/pituitary & 191,1943 & 4 & $1(0.5)$ & $3(1.4)$ & - \\
\hline Site unknown & 199 & 32 & $6(3.0)$ & $12(5.7)$ & $14(5.9)$ \\
\hline Other & $140-209^{c}$ & 66 & $21(10.6)$ & 26 (12.3) & $19(8.0)$ \\
\hline Diabetes mellitus and endocrine diseases & $240-289$ & 14 & $4(2.0)$ & $8(3.8)$ & $2(0.8)$ \\
\hline All circulatory disease & $390-458$ & 192 & $57(28.6)$ & 65 (30.8) & $70(29.4)$ \\
\hline Ischaemic heart disease & $410-414$ & 99 & $25(12.6)$ & 30 (14.2) & $44(18.5)$ \\
\hline Other heart disease & $420-429$ & 13 & $7(3.5)$ & $5(2.4)$ & $1(0.4)$ \\
\hline Cerebrovascular disease & $430-438$ & 47 & $11(5.5)$ & $20(9.5)$ & $16(6.7)$ \\
\hline Other circulatory disease & $390-409,440-458$ & 33 & $14(7.0)$ & $10(4.7)$ & 9 (3.8) \\
\hline Respiratory disease & $460-519$ & 55 & $11(5.5)$ & $11(5.2)$ & $33(13.9)$ \\
\hline Digestive disease & $520-577$ & 28 & 5 (2.5) & $10(4.7)$ & 13 (5.5) \\
\hline Violence & 800-999, E800-999 & 20 & $10(5.0)$ & $4(1.9)$ & $6(2.5)$ \\
\hline All other causes & All codes ${ }^{c}$ & 52 & $21(10.6)$ & $16(7.6)$ & $15(6.3)$ \\
\hline
\end{tabular}


Table 3. Risk of all and cause-specific mortality among $\mathbf{4 1 2 1}$ women recruited in Scotland to the RCGP Oral Contraception Study

\begin{tabular}{|c|c|c|c|c|c|}
\hline \multirow[b]{2}{*}{ Cause of death ${ }^{b}$} & \multirow{2}{*}{$\begin{array}{l}\text { Number of cigarettes } \\
\text { smoked daily at recruitment }\end{array}$} & \multicolumn{2}{|c|}{ Unadjusted } & \multicolumn{2}{|c|}{ Adjusted $^{a}$} \\
\hline & & HR & $95 \% \mathrm{Cl}$ & HR & $95 \% \mathrm{Cl}$ \\
\hline \multirow[t]{7}{*}{ All causes } & $<15$ & 2.01 & 1.65 to 2.44 & 1.99 & 1.74 to 2.27 \\
\hline & $\geq 15$ & 2.97 & 2.46 to 3.59 & 2.81 & 2.47 to 3.20 \\
\hline & History of serious illness ${ }^{c}$ & & & 1.73 & 1.54 to 1.95 \\
\hline & Contraceptive pill use statusc & & & 0.78 & 0.69 to 0.87 \\
\hline & Parity & & & 0.90 & 0.82 to 0.98 \\
\hline & Social class & & & 0.80 & 0.71 to 0.91 \\
\hline & Age & & & 1.07 & 1.06 to 1.08 \\
\hline \multirow[t]{2}{*}{ Any cancers } & $<15$ & 2.02 & 1.52 to 2.69 & 1.95 & 1.61 to 2.36 \\
\hline & $\geq 15$ & 2.71 & 2.04 to 3.60 & 2.51 & 2.08 to 3.05 \\
\hline \multirow[t]{2}{*}{ Circulatory disease } & $<15$ & 2.16 & 1.51 to 3.08 & 2.24 & 1.75 to 2.87 \\
\hline & $\geq 15$ & 3.05 & 2.15 to 4.33 & 2.87 & 2.25 to 3.68 \\
\hline \multirow[t]{2}{*}{ Respiratory disease } & $<15$ & 1.90 & 0.82 to 4.37 & 1.71 & 0.90 to 3.23 \\
\hline & $\geq 15$ & 7.49 & 3.78 to 14.8 & 8.18 & 4.95 to 13.5 \\
\hline \multirow[t]{2}{*}{ Other causes not specified } & $<15$ & 1.80 & 1.15 to 2.80 & 1.81 & 1.32 to 2.49 \\
\hline & $\geq 15$ & 2.23 & 1.42 to 3.51 & 2.19 & 1.58 to 3.03 \\
\hline
\end{tabular}

$H R=$ hazard ratio. ${ }^{a}$ Adjusted for age and social class at recruitment and history of serious illness, contraceptive pill use status, and parity. ${ }^{b}$ The number of deaths in each category is shown in Table 2. 'Entered as a time-dependent covariate.

Table 4. Number of women in Scotland admitted to hospital for specific conditions, by smoking status at recruitment to the RCGP Oral Contraception Study

\begin{tabular}{|c|c|c|c|c|c|}
\hline \multirow[b]{2}{*}{ Reason for admission } & \multirow[b]{2}{*}{ ICD-8 codes } & \multirow[b]{2}{*}{$\begin{array}{c}\text { All women } \\
(N=4121), n(\%)\end{array}$} & \multicolumn{3}{|c|}{ Number of cigarettes smoked daily at recruitment } \\
\hline & & & $\begin{array}{c}\text { Non-smoker } \\
(n=2063), n[\%]\end{array}$ & $\begin{array}{c}<15 \\
(n=1142), n(\%)\end{array}$ & $\begin{array}{c}\geq 15 \\
{[n=916), n(\%)}\end{array}$ \\
\hline Any reason & 000-999, all E & $3657(88.7)$ & $1808(87.6)$ & 1020 (89.3) & $829(90.5)$ \\
\hline Infectious and parasitic diseases & $000-136$ & $1656(40.2)$ & 767 (37.2) & $472(41.3)$ & $417(45.5)$ \\
\hline Any cancer & 140-209 & $667(16.2)$ & 256 (12.4) & $218(19.1)$ & $193(21.1)$ \\
\hline \multicolumn{6}{|l|}{ Cancer site } \\
\hline Large bowel and rectum & 153,154 & $67(1.6)$ & $33(1.6)$ & $17(1.5)$ & $17(1.9)$ \\
\hline Lung & 162 & $105(2.5)$ & $14(0.7)$ & $36(3.2)$ & $55(6.0)$ \\
\hline Breast & 174 & 226 (5.5) & 110 (5.3) & $67(5.9)$ & $49(5.3)$ \\
\hline Invasive cervix & 180 & $19(0.5)$ & $5(0.2)$ & $9(0.8)$ & $5(0.5)$ \\
\hline Uterine body & 182 & $20(0.5)$ & 7 (0.3) & $8(0.7)$ & $5(0.5)$ \\
\hline Ovary & 183 & $35(0.8)$ & $16(0.8)$ & $14(1.2)$ & $5(0.5)$ \\
\hline Other reproductive & 184 & $17(0.4)$ & $5(0.2)$ & $8(0.7)$ & $4(0.4)$ \\
\hline Other cancer & $140-209^{c}$ & 403 (9.8) & $147(7.1)$ & $145(12.7)$ & $111(12.1)$ \\
\hline Diabetes mellitus & 250 & $189(4.6)$ & $84(4.1)$ & $55(4.8)$ & $50(5.5)$ \\
\hline Other endocrine disease & 40-289, except 250 & $610(14.8)$ & $269(13.0)$ & $181(15.8)$ & $160(17.5)$ \\
\hline Mental health problems & $290-317$ & $308(7.5)$ & $102(4.9)$ & $91(8.0)$ & $115(12.6)$ \\
\hline All circulatory disease & $390-458$ & $1472(35.7)$ & 678 (32.9) & $420(36.8)$ & $374(40.8)$ \\
\hline Ischaemic heart disease & $410-414$ & 507 (12.3) & 194 (9.4) & $154(13.5)$ & $159(17.4)$ \\
\hline Other heart disease & $420-429$ & 367 (8.9) & 150 (7.3) & $99(8.7)$ & $118(12.9)$ \\
\hline Cerebrovascular disease & $430-438$ & $192(4.7)$ & $75(3.6)$ & $55(4.8)$ & $62(6.8)$ \\
\hline Other circulatory disease & $390-409,440-458$ & 1135 (27.5) & $543(26.3)$ & $307(26.9)$ & $285(31.1)$ \\
\hline Respiratory disease & $460-519$ & $781(19.0)$ & $289(14.0)$ & $235(20.6)$ & $257(28.1)$ \\
\hline Digestive disease & $520-577$ & 1556 (37.8) & 729 (35.3) & $441(38.6)$ & $386(42.1)$ \\
\hline Genitourinary disease & $580-629$ & $1964(47.7)$ & $981(47.6)$ & $560(49.0)$ & $423(46.2)$ \\
\hline Other conditions not specified & All codes ${ }^{c}$ & 3084 (74.8) & 1499 (72.7) & $876(76.7)$ & 709 (77.4) \\
\hline
\end{tabular}

ICD-8 = International Classification of Disease 8th revision. ${ }^{c}$ Except those codes listed above. 
Table 5. Risk of hospital admission for specific conditions among 4121 women in Scotland at recruitment to the RCGP Oral Contraception Study

\begin{tabular}{|c|c|c|c|c|c|}
\hline \multirow[b]{2}{*}{ Reason for hospital admission ${ }^{b}$} & \multirow{2}{*}{$\begin{array}{l}\text { Number of cigarettes } \\
\text { smoked daily at recruitment }\end{array}$} & \multicolumn{2}{|c|}{ Unadjusted } & \multicolumn{2}{|c|}{ Adjusted $^{a}$} \\
\hline & & HR & $95 \% \mathrm{Cl}$ & HR & $95 \% \mathrm{Cl}$ \\
\hline \multirow[t]{7}{*}{ First admission for any reason } & $<15$ & 1.10 & 1.02 to 1.19 & 1.05 & 0.98 to 1.12 \\
\hline & $\geq 15$ & 1.14 & 1.05 to 1.24 & 1.08 & 1.01 to 1.15 \\
\hline & History of serious illness ${ }^{c}$ & - & - & 1.41 & 1.31 to 1.51 \\
\hline & Pill status ${ }^{c}$ & - & - & 0.69 & 0.65 to 0.73 \\
\hline & Parity & - & - & 0.86 & 0.82 to 0.89 \\
\hline & Social class & - & - & 0.91 & 0.85 to 0.96 \\
\hline & Age & - & - & 0.98 & 0.97 to 0.98 \\
\hline \multirow[t]{2}{*}{ Infectious and parasitic diseases } & $<15$ & 1.14 & 1.02 to 1.28 & 1.10 & 1.00 to 1.20 \\
\hline & $\geq 15$ & 1.30 & 1.15 to 1.46 & 1.21 & 1.10 to 1.34 \\
\hline \multirow[t]{2}{*}{ Any cancer } & $<15$ & 1.63 & 1.36 to 1.95 & 1.62 & 1.42 to 1.85 \\
\hline & $\geq 15$ & 1.89 & 1.56 to 2.27 & 1.78 & 1.55 to 2.04 \\
\hline \multirow[t]{2}{*}{ Diabetes mellitus } & $<15$ & 1.24 & 0.89 to 1.75 & 1.10 & 0.87 to 1.40 \\
\hline & $\geq 15$ & 1.49 & 1.05 to 2.11 & 1.25 & 0.98 to 1.60 \\
\hline \multirow[t]{2}{*}{ Other endocrine disease } & $<15$ & 1.29 & 1.07 to 1.55 & 1.26 & 1.10 to 1.45 \\
\hline & $\geq 15$ & 1.48 & 1.22 to 1.80 & 1.46 & 1.27 to 1.69 \\
\hline \multirow[t]{2}{*}{ Mental health problems } & $<15$ & 1.70 & 1.28 to 2.26 & 1.63 & 1.33 to 2.00 \\
\hline & $\geq 15$ & 2.81 & 2.15 to 3.67 & 2.38 & 1.95 to 2.91 \\
\hline \multirow[t]{2}{*}{ All circulatory disease } & $<15$ & 1.16 & 1.03 to 1.31 & 1.16 & 1.06 to 1.27 \\
\hline & $\geq 15$ & 1.39 & 1.23 to 1.58 & 1.35 & 1.23 to 1.49 \\
\hline \multirow[t]{2}{*}{ Ischaemic heart disease } & $<15$ & 1.53 & 1.24 to 1.89 & 1.54 & 1.32 to 1.80 \\
\hline & $\geq 15$ & 2.08 & 1.69 to 2.57 & 1.91 & 1.63 to 2.23 \\
\hline \multirow[t]{2}{*}{ Other heart disease } & $<15$ & 1.25 & 0.97 to 1.61 & 1.35 & 1.12 to 1.62 \\
\hline & $\geq 15$ & 1.99 & 1.56 to 2.53 & 2.07 & 1.74 to 2.47 \\
\hline \multirow[t]{2}{*}{ Cerebrovascular disease } & $<15$ & 1.38 & 0.97 to 1.95 & 1.22 & 0.94 to 1.58 \\
\hline & $\geq 15$ & 2.04 & 1.45 to 2.85 & 2.05 & 1.61 to 2.61 \\
\hline \multirow[t]{2}{*}{ Other circulatory disease } & $<15$ & 1.05 & 0.91 to 1.21 & 1.20 & 0.92 to 1.13 \\
\hline & $\geq 15$ & 1.28 & 1.11 to 1.48 & 1.24 & 1.12 to 1.38 \\
\hline \multirow[t]{2}{*}{ Respiratory disease } & $<15$ & 1.57 & 1.32 to 1.87 & 1.50 & 1.32 to 1.70 \\
\hline & $\geq 15$ & 2.27 & 1.92 to 2.69 & 2.07 & 1.83 to 2.34 \\
\hline \multirow[t]{2}{*}{ Digestive disease } & $<15$ & 1.15 & 1.02 to 1.29 & 1.14 & 1.04 to 1.25 \\
\hline & $\geq 15$ & 1.31 & 1.16 to 1.48 & 1.27 & 1.16 to 1.39 \\
\hline \multirow[t]{2}{*}{ Genitourinary disease } & $<15$ & 1.06 & 0.96 to 1.18 & 1.05 & 0.97 to 1.14 \\
\hline & $\geq 15$ & 0.97 & 0.87 to 1.09 & 0.95 & 0.87 to 1.03 \\
\hline \multirow[t]{2}{*}{ Other conditions not specified } & $<15$ & 1.14 & 1.05 to 1.24 & 1.11 & 1.04 to 1.19 \\
\hline & $\geq 15$ & 1.18 & 1.08 to 1.29 & 1.15 & 1.07 to 1.23 \\
\hline
\end{tabular}

${ }^{a}$ Adjusted for age and social class at recruitment and history of serious illness, contraceptive pill use status, and parity. ${ }^{b}$ The number of women admitted in each category is shown in Table 4. ${ }^{c}$ Entered as a time-dependent covariate. HR = hazard ratio.

Table 6. Number of different types of hospital admissions among women in Scotland by smoking status at recruitment to the RCGP Oral Contraception Study

\begin{tabular}{|c|c|c|c|c|}
\hline \multirow[b]{2}{*}{$\begin{array}{l}\text { Number of different types } \\
\text { of hospital admissions }\end{array}$} & \multirow[b]{2}{*}{$\begin{array}{c}\text { All women } \\
(n=4121), n(\%)\end{array}$} & \multicolumn{3}{|c|}{ Number of cigarettes smoked daily at recruitment } \\
\hline & & $\begin{array}{l}\text { Non-smoker } \\
(n=2063), n(\%)\end{array}$ & $\begin{array}{c}<15 \\
(n=1142), n(\%)\end{array}$ & $\begin{array}{c}\geq 15 \\
(n=916), n(\%)\end{array}$ \\
\hline 0 & $464(11.3)$ & $255(12.4)$ & $122(10.7)$ & $87(9.5)$ \\
\hline 1 & $601(14.6)$ & $337(16.3)$ & 152 (13.3) & $112(12.2)$ \\
\hline 2 & $777(18.9)$ & $404(19.6)$ & 208 (18.2) & $165(18.0)$ \\
\hline 3 & $724(17.6)$ & 398 (19.3) & $194(17.0)$ & $132(14.4)$ \\
\hline$\geq 4$ & 1555 (37.7) & $669(32.4)$ & $466(40.8)$ & $420(45.9)$ \\
\hline
\end{tabular}

remained significantly increased in both women who smoked $<15$ cigarettes daily ladjusted HR $=1.99,95 \%$ confidence interval $[\mathrm{Cl}]=1.74$ to 2.27$)$ and those who smoked $\geq 15$ cigarettes daily ladjusted $\mathrm{HR}=2.81$, $95 \% \mathrm{Cl}=2.47$ to 3.20 ). Smoking any amount was associated with an increased risk of death from any cancer, circulatory disease, and other causes not specified. Among women who smoked $\geq 15$ cigarettes daily, the rate of death from respiratory disease was eight-times that of the non-smokers ladjusted $\mathrm{HR}=8.18,95 \% \mathrm{Cl}=4.95$ to 13.5 ). The increased risk of death from respiratory disease among women who smoked less 


\section{Table 7. Number of hospital admissions and total length of stay among women in Scotland by smoking status at recruitment to the RCGP Oral Contraception Study}

\begin{tabular}{|c|c|c|c|c|c|}
\hline \multirow[b]{2}{*}{ Characteristic } & \multirow[b]{2}{*}{$\begin{array}{l}\text { All women } \\
\text { ( } N=4121)\end{array}$} & \multicolumn{4}{|c|}{ Number of cigarettes smoked daily at recruitment } \\
\hline & & $\begin{array}{l}\text { Non-smokers } \\
(n=2063)\end{array}$ & $\begin{array}{c}<15 \\
(n=1142)\end{array}$ & $\begin{array}{c}\geq 15 \\
(n=916)\end{array}$ & $P$-value ${ }^{a}$ \\
\hline At least one admission, $n(\%)$ & $3657(88.7)$ & $1808(87.6)$ & $1020(89.3)$ & 829 (90.5) & \\
\hline $\begin{array}{l}\text { For women admitted at least or } \\
\text { Total number of admissions, } \\
\text { median (IQR) }\end{array}$ & $2(3-10)$ & $J(z-$ & 3 & & \\
\hline $\begin{array}{l}\text { Total length of stay (bed-days), } \\
\text { median (IQR) }\end{array}$ & $21(8-27)$ & 18 (7-38) & $23(8-50)$ & $26(11-59)$ & $<0.001$ \\
\hline
\end{tabular}

$1 Q R=$ interquartile range. ${ }^{a}$ Kruskal-Wallis test.

\section{Table 8. Number of admissions by speciality and type of admissions among women in Scotland with at least one admission, by smoking status at recruitment to the RCGP Oral Contraception Study}

\begin{tabular}{|c|c|c|c|c|c|}
\hline \multirow{2}{*}{$\begin{array}{l}\text { Admitting } \\
\text { specialty and } \\
\text { number of } \\
\text { admissions }\end{array}$} & \multirow[b]{2}{*}{$\begin{array}{l}\text { All admitted } \\
\text { women, } \\
\text { (N=3657), } n(\%)\end{array}$} & \multicolumn{4}{|c|}{ Number of cigarettes smoked daily at recruitment } \\
\hline & & $\begin{array}{c}\text { Non-smokers, } \\
(n=1808) \\
n(\%)\end{array}$ & $\begin{array}{c}<15, \\
(n=1020), \\
n(\%)\end{array}$ & $\begin{array}{c}\geq 15 \\
(n=829) \\
n(\%)\end{array}$ & $P$-value \\
\hline \multicolumn{2}{|l|}{ Surgical } & & & & 0.486 \\
\hline 0 & $807(22.1)$ & $408(22.6)$ & $219(21.5)$ & $180(21.7)$ & \\
\hline 1 & 809 (22.1) & $409(22.6)$ & $232(22.8)$ & $168(20.3)$ & \\
\hline 2 & 602 (16.5) & $308(17.0)$ & $159(15.6)$ & $135(16.3)$ & \\
\hline$\geq 3$ & 1439 (39.4) & $683(37.8)$ & $410(40.2)$ & $346(41.7)$ & \\
\hline \multicolumn{2}{|l|}{ Cardiology } & & & & $<0.001$ \\
\hline 0 & 3283 (89.8) & 1660 (91.8) & 907 (88.9) & $716(86.4)$ & \\
\hline$\geq 1$ & $374(10.2)$ & $148(8.2)$ & $113(11.1)$ & $113(13.6)$ & \\
\hline \multicolumn{2}{|l|}{ Respiratory } & & & & $<0.001$ \\
\hline 0 & 3011 (82.3) & $1544(85.4)$ & $831(81.5)$ & $636(76.7)$ & \\
\hline 1 & $398(10.9)$ & $181(10.0)$ & 119 (11.7) & 98 (11.8) & \\
\hline 2 & $133(3.6)$ & $50(2.8)$ & 40 (3.9) & $43(5.2)$ & \\
\hline$\geq 3$ & $115(3.1)$ & $33(1.8)$ & $30(2.9)$ & $52(6.3)$ & \\
\hline \multicolumn{2}{|l|}{ Other medical } & & & & $<0.001$ \\
\hline 0 & 504 (13.8) & 277 (15.3) & $139(13.6)$ & $88(10.6)$ & \\
\hline 1 & 816 (22.3) & 438 (24.2) & 213 (20.9) & 165 (19.9) & \\
\hline 2 & $646(17.7)$ & 322 (17.8) & $173(17.0)$ & $151(18.2)$ & \\
\hline$\geq 3$ & $1691(46.2)$ & $771(42.6)$ & $495(48.5)$ & 425 (51.3) & \\
\hline \multicolumn{2}{|c|}{ Intensive therapy unit } & & & & $<0.001$ \\
\hline 0 & 3283 (89.8) & $1664(92.0)$ & $915(89.7)$ & 704 (84.9) & \\
\hline$\geq 1$ & $374(10.2)$ & $14(8.0)$ & 105 (10.3) & $125(15.1)$ & \\
\hline \multicolumn{2}{|c|}{ Accident and emergency } & & & & 0.738 \\
\hline 0 & $3525(96.4)$ & 1741 (96.3) & $987(96.8)$ & $797(96.1)$ & \\
\hline$\geq 1$ & $132(3.6)$ & $97(3.7)$ & $33(3.2)$ & $32(3.9)$ & \\
\hline \multicolumn{6}{|c|}{ Type of admission } \\
\hline \multicolumn{2}{|c|}{ Emergency admission } & & & & $<0.001$ \\
\hline 0 & $956(26.1)$ & $530(29.3)$ & $251(24.6)$ & $175(21.1)$ & \\
\hline 1 & $951(26.0)$ & $501(27.7)$ & $257(25.2)$ & 193 (23.3) & \\
\hline 2 & $602(16.5)$ & $311(17.2)$ & $163(16.0)$ & $128(15.4)$ & \\
\hline$\geq 3$ & $1148(31.4)$ & $466(25.8)$ & 349 (34.2) & $333(40.2)$ & \\
\hline \multicolumn{2}{|c|}{ Inpatient admission } & & & & $<0.001$ \\
\hline 0 & $329(9.0)$ & $195(10.8)$ & 74 (7.3) & $60(7.2)$ & \\
\hline 1 & 668 (18.3) & $347(19.2)$ & 189 (18.5) & 132 (15.9) & \\
\hline 2 & $530(14.5)$ & $287(15.9)$ & $138(13.5)$ & 105 (12.7) & \\
\hline$\geq 3$ & $2130(58.2)$ & $979(54.1)$ & $619(60.7)$ & $532(64.2)$ & \\
\hline
\end{tabular}

was not statistically significant, although the number of women affected was small.

Smoking was associated with hospital admission for any reason and for several specified conditions (Table 4). When there were differences between smoking groups, the proportion of women admitted to hospital tended to increase with the number of cigarettes smoked.

The unadjusted Cox regression models showed an increased risk of admission to hospital for any reason among smokers (Table 5). Smoking was associated with many specific causes of admission, usually with a higher risk among women smoking $\geq 15$ cigarettes daily. Following adjustment for age, social class, parity, contraceptive pill use, and history of serious illness, the increased risk of admission to hospital for any reason remained significantly elevated in women smoking $\geq 15$ cigarettes daily. Elevated risk estimates were also seen in one or both smoking groups, for infectious and parasitic disease; any cancer; non-diabetic endocrine disease; mental health problems; all circulatory disease and specific cardiovascular groups; respiratory disease; digestive disease; and conditions not specified. Owing to smaller event numbers, Cox regression was not calculated for the specific cancer sites, although Table 4 gives an indication of the likely relationship.

Compared to non-smokers, a larger proportion of women who smoked were admitted to hospital for four or more different reasons (Table 6). Of those admitted to hospital, women who smoked were admitted more often, with a longer total length of stay (Table 7). In terms of admission specialty, compared to nonsmokers, women who smoked had a higher proportion of admissions to cardiology, respiratory, other medical and intensive therapy unit specialties lall $P<0.001$; Table 8). There were no differences between nonsmokers and those who smoked in the proportion of women admitted to surgical wards or to accident and emergency. Women who smoked were more likely than non-smokers to be admitted as an emergency and as an inpatient.

Life-tableanalysis showed that the median survival age was similar among women who were non-smokers, regardless of whether they lived in Scotland or elsewhere in the UK (Table 9). However, among women who smoked, the median survival age was lower among women who lived in Scotland $K<15$ cigarettes daily, median survival age $=82.0$ years; $\geq 15$ cigarettes daily, median survival age $=79.6$ years) 
Table 9. Life table of women living in Scotland and elsewhere in the UK at recruitment to the RCGP Oral Contraception Study

Women surviving, \%

\begin{tabular}{lcccccc} 
& \multicolumn{3}{c}{$\begin{array}{c}\text { Number of cigarettes daily, } \\
\text { Scotland }\end{array}$} & \multicolumn{3}{c}{$\begin{array}{c}\text { Number of cigarettes daily, } \\
\text { elsewhere in the UK }\end{array}$} \\
\cline { 2 - 7 } years & Non-smoker to age, & $\mathbf{2 1 5}$ & $\mathbf{2 1 5}$ & Non-smoker & $\mathbf{< 1 5}$ & $\mathbf{2 1 5}$ \\
\hline 50 & 99 & 99 & 99 & 98 & 98 & 97 \\
\hline 60 & 97 & 94 & 92 & 96 & 94 & 91 \\
\hline 70 & 91 & 84 & 74 & 91 & 87 & 79 \\
\hline 80 & 77 & 53 & 46 & 79 & 70 & 57 \\
\hline 85 & 58 & 28 & 11 & 68 & 59 & 44 \\
\hline Median survival age & 89.3 & 82.0 & 79.6 & 90.0 & 88.4 & 83.8 \\
\hline
\end{tabular}

than women who lived elsewhere in the UK $\mid<15$ cigarettes daily, median survival age $=88.4$ years; $\geq 15$ cigarettes daily, median survival age $=83.8$ years). While the unadjusted Cox regression models showed that smoking was usually associated with all-cause mortality and risk of death from cancer, circulatory disease, respiratory disease, and all other causes, regardless of place of recruitment, the HRs tended to be highest among women recruited in Scotland (Table 10). These relationships remained following adjustment for age, social class, parity, contraceptive pill use, and history of serious illness.

\section{DISCUSSION}

\section{Summary}

This study provides new evidence about the burden of smoking among young women living in Scotland, in terms of future hospital admissions, in addition to confirming the relationship with future mortality. Furthermore, the mortality results suggest greater harmful effects among smokers living in Scotland compared with smokers residing elsewhere in the UK.

\section{Table 10. Comparison of the effects of smoking on all-cause and cause-specific mortality risk by location of recruitment to the RCGP Oral Contraception Study $(N=38$ 894)}

\begin{tabular}{|c|c|c|c|c|c|c|}
\hline \multirow[b]{2}{*}{ Cause of death } & \multirow{2}{*}{$\begin{array}{l}\text { Number of } \\
\text { cigarettes smoked daily } \\
\text { at recruitment (location] }\end{array}$} & \multirow{2}{*}{$\begin{array}{l}\text { Number }(\%) \\
\text { of deaths }\end{array}$} & \multicolumn{2}{|c|}{ Unadjusted } & \multicolumn{2}{|c|}{ Adjusteda } \\
\hline & & & HR & $95 \% \mathrm{Cl}$ & HR & $95 \% \mathrm{Cl}$ \\
\hline \multirow[t]{10}{*}{ All causes } & Non-smokers (all UK) & $2058(10.7)$ & 1.00 & - & 1.00 & - \\
\hline & $<15$ (elsewhere in UK) & $1296(14.0)$ & 1.47 & 1.37 to 1.58 & 1.53 & 1.46 to 1.61 \\
\hline & $\geq 15$ (elsewhere in UK) & $1420(22.2)$ & 2.45 & 2.29 to 2.62 & 2.36 & 2.25 to 2.48 \\
\hline & $<15$ (Scotland) & 211 (18.5) & 1.95 & 1.69 to 2.25 & 2.05 & 1.85 to 2.26 \\
\hline & $\geq 15$ (Scotland) & $238(26.0)$ & 2.86 & 2.50 to 3.27 & 2.88 & 2.62 to 3.16 \\
\hline & History of serious illness ${ }^{b}$ & - & - & - & 2.43 & 2.33 to 2.54 \\
\hline & Contraceptive pill use status & - & - & - & 0.68 & 0.66 to 0.71 \\
\hline & Parity ${ }^{b}$ & - & - & - & 0.88 & 0.85 to 0.90 \\
\hline & Social class & - & - & - & 0.79 & 0.75 to 0.82 \\
\hline & Age & - & - & - & 1.069 & 1.066 to 1.072 \\
\hline \multirow[t]{5}{*}{ Any cancers } & Non-smokers (all UK) & 989 (4.7) & 1.00 & & 1.00 & \\
\hline & $<15$ (elsewhere in UK) & $524(5.6)$ & 1.24 & 1.11 to 1.38 & 1.32 & 1.22 to 1.42 \\
\hline & $\geq 15$ (elsewhere in UK) & $615(9.6)$ & 2.20 & 1.99 to 2.42 & 2.14 & 1.99 to 2.30 \\
\hline & $<15$ (Scotland) & $97(8.5)$ & 1.86 & 1.51 to 2.29 & 1.89 & 1.64 to 2.18 \\
\hline & $\geq 15$ (Scotland) & 99 (10.8) & 2.45 & 2.00 to 3.02 & 2.41 & 2.10 to 2.77 \\
\hline \multirow[t]{5}{*}{ Circulatory disease } & Non-smokers (all UK) & $510(2.4)$ & 1.00 & & 1.00 & \\
\hline & $<15$ (elsewhere in UK) & 365 (3.9) & 1.67 & 1.46 to 1.91 & 1.78 & 1.61 to 1.96 \\
\hline & $\geq 15$ (elsewhere in UK) & $412(6.4)$ & 2.87 & 2.52 to 3.27 & 2.77 & 2.51 to 3.05 \\
\hline & $<15$ (Scotland) & $65(5.7)$ & 2.43 & 1.88 to 3.14 & 2.72 & 2.27 to 3.25 \\
\hline & $\geq 15$ (Scotland) & $70(7.6)$ & 3.40 & 2.65 to 4.37 & 3.50 & 2.94 to 4.18 \\
\hline \multirow[t]{5}{*}{ Respiratory disease } & Non-smokers (all UK) & $158(0.7)$ & 1.00 & & 1.00 & \\
\hline & $<15$ (elsewhere in UK) & $152(1.6)$ & 2.26 & 1.81 to 2.82 & 2.36 & 2.01 to 2.78 \\
\hline & $\geq 15$ (elsewhere in UK) & 184 (2.9) & 4.19 & 3.39 to 5.18 & 4.01 & 3.43 to 4.69 \\
\hline & $<15$ (Scotland) & $11(1.0)$ & 1.34 & 0.73 to 2.47 & 1.10 & 0.68 to 1.77 \\
\hline & $\geq 15$ (Scotland) & $33(3.6)$ & 5.30 & 3.64 to 7.70 & 5.26 & 4.04 to 6.85 \\
\hline \multirow[t]{5}{*}{ Other causes not specified } & Non-smokers (all UK) & 401 (1.9) & 1.00 & & 1.00 & \\
\hline & $<15$ (elsewhere in UK) & 255 (2.7) & 1.49 & 1.27 to 1.74 & 1.49 & 1.32 to 1.68 \\
\hline & $\geq 15$ (elsewhere in UK) & 209 (3.3) & 1.84 & 1.56 to 2.18 & 1.76 & 1.55 to 2.01 \\
\hline & $<15$ (Scotland) & $38(3.3)$ & 1.80 & 1.29 to 2.52 & 2.03 & 1.60 to 2.58 \\
\hline & $\geq 15$ (Scotland) & $36(3.9)$ & 2.22 & 1.58 to 3.12 & 2.44 & 1.91 to 3.12 \\
\hline
\end{tabular}

${ }^{a}$ Adjusted for age and social class at recruitment and history of serious illness, contraceptive pill use status, and parity. ${ }^{b}$ Entered as a time-dependent covariate. $H R=$ hazard ratio. 


\section{Strengths and limitations}

Study strengths include its prospective design and the ability to examine the long-term effects (up to 41 years) of smoking at a young age on risk of hospital admission, as well as mortality. Smoking information was collected at recruitment, and smoking habits within the cohort have changed over time. When a subset of the cohort completed a health survey in the mid-1990s, a higher proportion of the women had stopped smoking than started. ${ }^{20}$ Assuming a similar pattern of change among the nested cohort of women recruited in Scotland, then disproportionately more women will have been misclassified as current smokers (when actually at lower risk of smoking-related illness) than those misclassified as non-smokers (who will have been at increased risk of these conditions). Thus the study is likely to have underestimated the effects of smoking.

Since the RCGP Oral Contraception Study does not hold any identifiable information about the cohort, it had to be assumed that women whose study numbers were not included in the linked data file from ISD were recruited elsewhere in the UK. This means that in the analyses comparing mortality among women living in Scotland and elsewhere, women who had been recruited in Scotland but who left the study before the cohort was flagged at the NHS Central Registries will have been misclassified as living elsewhere in the UK. The effect of such misclassification will be towards the null, since the risk estimates associated with smoking were generally higher among women recruited in Scotland. However, the number of women misclassified is likely to have been small and so is unlikely to substantially bias the study findings.

It was possible to adjust for a number of important confounders, such as social class, past medical history, and use of the contraceptive pill. However, residual confounding, for example from differences in diet, alcohol intake, and other lifestyle factors, may explain the observed findings. For example, residual confounding might have occurred if there were differential effects among smokers and non-smokers living in different parts of the country Isince there were no differences in survival among non-smokers recruited from different UK areas). For example, the higher mortality risks associated with smoking among women living in Scotland might be partially explained if smokers living elsewhere were more likely to reduce the number of cigarettes they smoked, or to reduce or stop smoking at a younger age than smokers living in Scotland.

\section{Comparison with existing literature}

Based on smoking habits assessed, on average, at the age of 29 years, this study found that women who smoked had an increased risk of all-cause mortality compared with non-smokers. The increased mortality risk was highest among smokers who consumed $\geq 15$ cigarettes daily. The 1951 British Doctors' Study followed 6194 women for 22 years and also found that death rates increased with the number of cigarettes smoked.' Doll et al found that $16 \%$ of all female deaths were due to ischaemic heart disease, which is similar to the proportion (99/648; $15.3 \%$ ) of such deaths found in the present study.

The Oxford Family Planning Association Study of 17032 women aged 25-34 years at recruitment between 1968 and 1974 investigated smoking-related mortality during 479400 woman-years of observation. ${ }^{2}$ Women who smoked at least 15 cigarettes daily at recruitment had more than twice the risk of all-cause mortality than neversmokers (relative risk $[R R]=2.14,95 \%$ $\mathrm{Cl}=1.81$ to 2.53). An increased risk of allcause mortality was also associated with smoking fewer cigarettes $(R R=1.24,95 \%$ $\mathrm{Cl}=1.03$ to 1.49). These risk estimates concur with the present findings. The Oxford Family Planning Association Study also found that women smoking $>15$ cigarettes had a sixfold increased risk of death from respiratory disease $(R R=6.4,95 \% \mathrm{Cl}=3.2$ to 13.2) but there was no increased risk among women who smoked $\leq 15(R R=1.2$, $95 \% \mathrm{Cl}=0.4$ to 3.4). The UK Million Women Study recently reported, based on 12 years of follow-up, a more than threefold increased risk of mortality associated with smoking $\geq 20$ cigarettes daily $(\mathrm{RR}=3.74,95 \% \mathrm{Cl}=3.64$ to 3.85 ). Women who smoked $<10$ cigarettes daily had almost twice the risk of death as never-smokers $(\mathrm{RR}=1.98,95 \% \mathrm{Cl}=1.91$ to 2.04). ${ }^{21}$ The present study found similar patterns of mortality risk.

Prospective cohort studies conducted in the US also support the present findings of increased mortality risks associated with smoking in women. During 12 years of follow-up of 117001 female registered nurses, mortality risk estimates were calculated for former and current smokers as groups, and among current smokers, by the number of cigarettes smoked daily. ${ }^{4}$ Both former and current smoking were associated with all-cause mortality and death from cardiovascular disease, cancer, and external causes of injury, with the highest relative risks found among women who smoked at least 35 cigarettes daily.

By linking a cross-sectional health survey 
conducted in 1978 to the Western Australian Hospital Morbidity Data System, English et al followed up 1459 men and 1771 women, to investigate the impact of smoking on use of hospital services. ${ }^{13}$ Rates of hospital admissions for all conditions combined, and for digestive disorders, were significantly higher among female current or former smokers than never-smokers at baseline. An increased risk of hospital admission for circulatory and respiratory disorders was found only among women who were current smokers. There was a positive doseresponse relationship between the number of cigarettes smoked daily and the risk of hospital admissions for any reason. The present study also found that smoking at a young age was associated with an increased future risk of hospital admission for any reason, or for circulatory, respiratory, or digestive disease causes. However, the Australian study included fewer women than the present study and examined fewer reasons for admissions.

The impact of smoking on use of hospital services for reasons related to injury and accidents, and cardiovascular musculoskeletal, and respiratory disease, was examined in 2668 women living in northeast Finland and aged 19-63 years in 1980, when they completed a selfadministered questionnaire. ${ }^{11}$ The women were then followed for 16 years through the national discharge registry. Current smokers had $49 \%(95 \% \mathrm{Cl}=29 \%$ to $71 \%)$ more hospital days for any reason, and $461 \%(95 \% \mathrm{Cl}=88 \%$ to $1573 \%)$ more hospital days because of cardiovascular disease than never-smokers. The present study found that, among women who smoke, there was both a greater likelihood of being admitted for many specific reasons and an increased chance of having been admitted for multiple different reasons, suggesting a cumulative burden of disease from smoking.

Two US female military cohort studies have examined the relationship between smoking at a young age and subsequent hospitalisation. 12,14 Robbins et al studied 87991 men and women on active duty in the US Army who, between 1987 and 1998, completed at least two health-risk appraisals. ${ }^{12}$ The mean age of the cohort at baseline was 28.5 years and $21.1 \%$ of the women were current smokers. Current and former female smokers had an increased risk of being hospitalised for reasons unrelated to injury or pregnancy lcurrent smokers: $\mathrm{RR}=1.25,95 \% \mathrm{Cl}=1.14$ to 1.37 ; former smokers: $\mathrm{RR}=1.13,95 \% \mathrm{Cl}=1.01$ to 1.26). Similarly, between 1996 and 1997, 5503 female US Navy recruits with a mean age of
19.7 years $(S D=2.75$ years $)$ completed a survey about their smoking behaviour, which was then linked to the Career History Archival Medical and Personnel System to collect data about subsequent hospitalisation. ${ }^{14}$ In comparison to daily smokers, neversmokers were less likely to be admitted to hospital for any reason (RR $=0.90,95 \%$ $\mathrm{Cl}=0.81$ to 0.99 ) or for musculoskeletal causes ( $R R=0.35,95 \% \mathrm{Cl}=0.19$ to 0.63 ). Although both cohorts examined healthy women for limited durations (2.4 years and 8 years respectively), their findings concur with those of the present study.

\section{Implications for research and practice}

The finding that median survival age was lower among smoking women living in Scotland compared with those in the remainder of the UK is intriguing. The generally higher mortality risk estimates among women who smoke recruited in Scotland compared with those recruited elsewhere was also noteworthy.

A 'Scottish effect', in which higher mortality rates have been found in Scotland compared with the rest of the UK, even after allowing for deprivation, has been described previously. 22,23 The British Women's Heart and Health Study investigated the prevalence of cardiovascular risk factors among 4286 women aged 60-79 years and found that women living in Scotland had a 53\% greater chance of having cardiovascular disease than women in England or Wales. ${ }^{24}$ The increase was not explained by differences in cardiovascular risk factors such as smoking or social class, or differences in use of aspirin or statins. The present study also found higher adjusted HRs for fatal circulatory disease among women who smoke and were recruited in Scotland than among those recruited from elsewhere in the UK. Reasons for these differences require further investigation.

The results of this study show that smoking at a young age in women increases the risk of subsequent hospital admission, overall, and for a variety of different serious conditions. This effect accumulates, so that smokers have a greater burden of hospital admission for different reasons. Smoking also increases the long-term risk of allcause mortality and death from a variety of specific causes. The harmful effects appear to be greater among women who smoke and live in Scotland, compared with those residing elsewhere in the UK. All of these results highlight the need to maintain effective interventions to reduce smoking among women, especially among those living in Scotland. this article on the Discussion Forum: http://www.rcgp.org.uk/bjgp-discuss 


\section{REFERENCES}

1. Doll R, Gray R, Hafner B, et al. Mortality in relation to smoking: 22 years observations on female British doctors. BMJ 1980; 280(6219): 967-971.

2. Vessey M, Painter R, Yeates D. Mortality in relation to oral contraceptive use and cigarette smoking. Lancet 2003; 362(9379): 185-191.

3. Thun MJ, Day-Lally CA, Calle EE, et al. Excess mortality among cigarette smokers: changes in a 20 year interval. Am J Public Health 1995; 85(9): 1223 1230 .

4. Kawachi I, Colditz GA, Stampfer MJ, et al. Smoking cessation in relation to total mortality rates in women. A prospective cohort study. Ann Intern Med 1993;

119(10): 992-1000.

5. Clennell S, Kuh D, Guralnik JM, et al. Characterisation of smoking behaviour across the life course and its impact on decline in lung function and all-cause mortality: evidence from a British birth cohort. J Epidemiol Community Health 2008; 62(12): 1051-1056.

6. US Department of Health and Human Services. Women and smoking. A report of the Surgeon General. Rockville, MD: Office of the Surgeon General, 2001.

7. Office for National Statistics. Deaths by age, sex and underlying cause, 2010 registrations (England and Wales). http://www.ons.gov.uk/ons/ dcp171778_239518.pdf (accessed 30 Jun 2013).

8. General Register Office for Scotland. Deaths, numbers and rates, by sex, age and cause, Scotland, 2010. http://www.gro-scotland.gov.uk/statistics/theme/vitalevents/general/ref-tables/2010/deaths-causes.html laccessed 24 Jun 2013).

9. Northern Ireland Statistics and Research Agency. Deaths, by sex, age and cause, 2009 (Northern Ireland). http://www.nisra.gov.uk/demography/default.asp14.htm (accessed 24 Jun 2013)

10. Robinson S, Harris H, Dunstan S (eds.). Smoking and drinking among adults, 2009. A report on the 2009 General Lifestyle Survey. Newport: Office for National Statistics, 2011.

11. Haapanen-Niemi N, Miilunpalo S, Vuori I, et al. The impact of smoking, alcohol consumption, and physical activity on use of hospital services. Am J Public Health 1999; 89(5): 691-698.

12. Robbins AS, Fonseca VP, Chao SY, et al. Short term effects of cigarette smoking on hospitalisation and associated lost workdays in a young healthy population. Tob Control 2000; 9(4): 389-396.
13. English DR, Vu HT, Knuiman MW. The impact of smoking on use of hospital services: the Busselton Study. Aust N Z J Public Health 2002; 26(3): 225-230.

14. Woodruff $\mathrm{SI}$, Conway TL, Shillington AM, et al. Cigarette smoking and subsequent hospitalization in a cohort of young US Navy female recruits. Nicotine Tob Res 2010; 12(4): 365-373.

15. Hanlon P, Lawder R, Elders A, et al. An analysis of the link between behavioural, biological and social risk factors and subsequent hospital admission in Scotland. J Public Health (Oxf) 2007; 29(4): 405-412.

16. Royal College of General Practitioners. Oral contraceptives and health. Tunbridge Wells: Pitmen Medical, 1974

17. General Registrar Office. Classification of occupations. London: HMSO, 1966.

18. World Health Organization. International classification of disease, injuries and causes of death, 8th revision. Geneva: WHO, 1967.

19. Allison PD. Survival analysis using SAS: a practical guide, 2nd edn. Cary, NC SAS Institute Inc., 2010

20. Owen-Smith V, Hannaford PC, Warskyj M, et al. Effects of changes in smoking status on risk estimates for myocardial infarction among women recruited for the Royal College of General Practitioners' Oral Contraception Study in the UK. J Epidemiol Community Health 1998; 52(7): 420-424.

21. Pirie K, Peto R, Reeves GK, et al, Million Women Study Collaborators. The 21st century hazards of smoking and benefits of stopping: a prospective study of one million women in the UK. Lancet 2013; 381(9861): 133-141.

22. Hanlon P, Walsh D, Buchanan D, et al. Chasing the Scottish effect: why Scotland needs a step-change in health if it is to catch up with the rest of Europe. Glasgow: Public Health Institute for Scotland, Information and Statistics Division, 2001

23. Hanlon P, Lawder RS, Buchanan D, et al. Why is mortality higher in Scotland than in England and Wales? Decreasing influence of socioeconomic deprivation between 1981 and 2001 supports the existence of a 'Scottish Effect'. J Public Health (Oxf) 2005; 27(2): 199-204.

24. Lawlor DA, Bedford C, Taylor M, Ebrahim S. Geographical variation in cardiovascular disease, risk factors, and their control in older women: British Women's Heart and Health Study. J Epidemiol Community Health 2003; 57(2): $134-140$. 